ONLINE MUTATION REPORT

\title{
Four common glomulin mutations cause two thirds of glomuvenous malformations ("familial glomangiomas"): evidence for a founder effect
}

\author{
P Brouillard, M Ghassibé, A Penington, L M Boon, A Dompmartin, I K Temple, M Cordisco, \\ D Adams, F Piette, J I Harper, S Syed, F Boralevi, A Taïeb, S Danda, E Baselga, O Enjolras, \\ J B Mulliken, M Vikkula
}

J Med Genet 2005;42:e13 (http://www.jmedgenet.com/cgi/content/full/42/2/e13). doi: 10.1136/jmg.2004.024174

\begin{abstract}
Background: Glomuvenous malformation (GVM) ("familial glomangioma") is a localised cutaneous vascular lesion histologically characterised by abnormal smooth muscle-like "glomus cells" in the walls of distended endothelium lined channels. Inheritable GVM has been linked to chromosome $1 \mathrm{p} 21-22$ and is caused by truncating mutations in glomulin. A double hit mutation was identified in one lesion. This finding suggests that GVM results from complete localised loss of function and explains the paradominant mode of inheritance.

Objective: To report on the identification of a mutation in glomulin in 23 additional families with GVM.

Results: Three mutations are new; the others have been described previously. Among the 17 different inherited mutations in glomulin known up to now in 43 families, the 157delAAGAA mutation is the most common and was present in 21 families (48.8\%). Mutation $108 C \rightarrow A$ was found in five families (11.8\%), and the mutations $554 \mathrm{del}+556 \mathrm{de} / \mathrm{CCT}$ and $1179 \mathrm{delCAA}$ were present together in two families (4.7\% each). Polymorphic markers suggested a founder effect for all four mutations.

Conclusions: Screening for these mutations should lead to a genetic diagnosis in about $70 \%$ of patients with inherited GVM. So far, a mutation in glomulin has been found in all GVM families tested, thus demonstrating locus homogeneity.
\end{abstract}

n the past, glomuvenous malformations (GVM, MIM 138000) were improperly called "glomangiomas" or "glomus tumours." GVM are vascular malformations and should be distinguished from paragangliomas (MIM 115310 , 168000, and 605373) and from the (subungual) solitary glomus tumours. ${ }^{1}$ Usually, GVM can be differentiated clinically from sporadic common venous malformations or inheritable cutaneomucosal venous malformation (VMCM, MIM 600195). GVM are often present at birth and slowly expand during childhood (fig 1). They are nodular and multifocal, rather than localised, frequently hyperkeratotic with a cobblestone-like appearance, and their colour varies from pink to purplish dark blue, as compared with the bluish hue of the typical venous malformations. ${ }^{2}$ In addition, GVM are mainly located on the extremities, involve skin and subcutis, cannot be completely emptied by compression, and are often painful on palpation. In contrast, venous malformations commonly affect muscle and joints, can easily be emptied by compression, and are not usually painful on palpation. $^{2}$ Proper diagnosis is important as venous malformations are symptomatically improved by elastic stockings, whereas compression causes GVM to be painful. Resection and sclerotherapy are alternatives for both GVM and venous malformations. ${ }^{2}$

GVM is histologically characterised by distended vascular channels surrounded by variable numbers of mural "glomus cells". ${ }^{3-5}$ Glomus cells stain positively for smooth muscle $\alpha$ actin and vimentin, whereas they are negative for desmin, von Willebrand factor, and S-100 neuronal marker. ${ }^{6}$ In addition, glomus cells have electronmicroscopic characteristics of smooth muscle ${ }^{7}$ and thus are considered to be abnormally differentiated vascular smooth muscle cells. ${ }^{6}$

We previously reported that families with autosomal dominant inheritance of GVM link to chromosome $1 p 21$ $22,{ }^{3}$ and we identified linkage disequilibrium for seven families in a region of $1.48 \mathrm{Mbp}$ in the $V M G L O M$ locus. ${ }^{8}$ By positional cloning using YAC and PAC based physical maps, ${ }^{9}$ we identified a novel gene, glomulin (glmn), with unknown function, mutated in GVM. Altogether, 14 different germline mutations were documented in affected individuals in 20 distinct families with high, but not complete, penetrance. Most mutations were thought to result in haploinsufficiency. Interestingly, we identified a somatic "second hit" mutation, also predicted to result in a truncated protein, in one patient, suggesting that the lesions arise because of complete localised loss of function of glomulin. ${ }^{5}$ Thus GVM are inherited in a paradominant mode.

Our aim in this study was to identify additional mutations in glomulin in order to evaluate locus homogeneity and a possible founder effect. In addition, we hoped to uncover mutations that might increase our understanding of the function of glomulin. In all, we found seven different mutations in the 23 new families tested. Three mutations were novel and the four others, which had been documented previously, were found in 20 new families. Haplotypic analysis of the families with these common mutations revealed a strong founder effect. Finally, as all families with clinically unequivocal GVM proved to have a germline mutation, altered function of glomulin seems to be the only primary cause of the vascular lesions.

\section{METHODS}

\section{Families and patients}

Blood samples were collected from patients of 23 novel families with transmitted GVM (fig 2). All affected individuals had lesions resembling those described previously. ${ }^{2} 5$ Informed consent was obtained for each participant, as

Abbreviations: GVM, glomuvenous malformation 

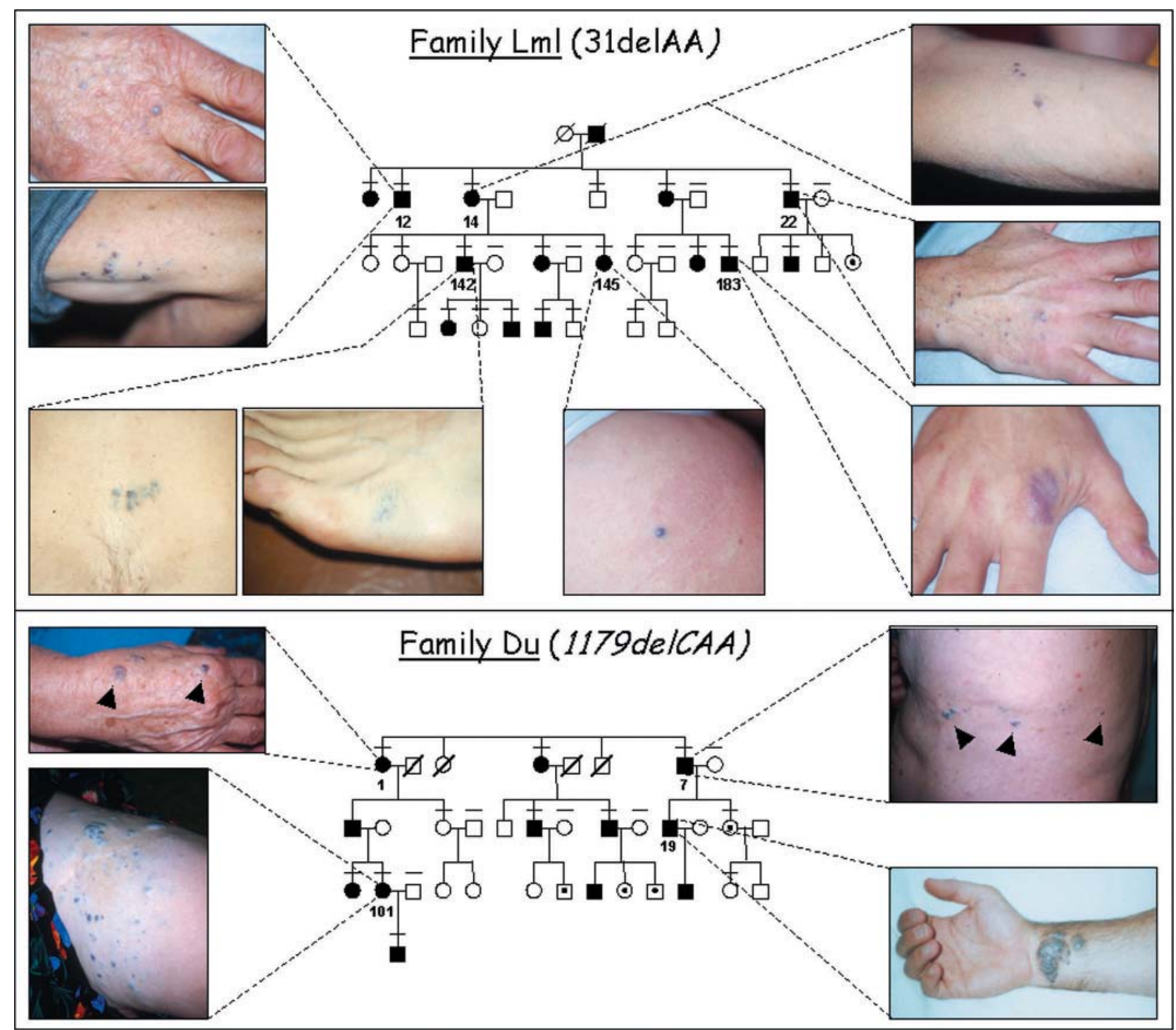

Figure 1 Phenotypic variation in glomuvenous malformations. Most lesions are small and localised. Individual Du-19 has a large raised lesion on wrist. Lml-183 has a plaque-like purple lesion. Du-101 has a broad cobblestone-like lesion. Small horizontal bars indicate individuals examined clinically. Reproduced with permission.

approved by the ethics committee of the medical faculty of the Université catholique de Louvain, Brussels, Belgium.

\section{Screening on genomic DNA}

Screening for mutations was done on genomic DNA from one or two patients per family. Venous blood samples were drawn from all participants and DNA was extracted from the buffy coats (QIAamp DNA blood mini kit; Qiagen Inc, Valencia, California, USA) or from whole blood (DNA purification kit; Gentra Systems Inc, Minneapolis, Minnesota, USA). Mutational screening was by SSCP, heteroduplex, and size difference analyses, as described. ${ }^{5}$ Fragments showing abnormal migration were reamplified and sequenced on a CEQ2000 capillary sequencer (Beckman Coulter).

\section{Segregation of mutations}

Segregation of the three novel mutations (738insT, 1150delAG and 1293delA+1296delAAA) was assessed by sequencing. Mutations $108 C \rightarrow A, \quad$ 157delAAGAA and 1179delCAA were tested by allele-specific PCR (table 1) and mutation 554delA+556delCCT, which creates a SpeI restriction enzyme cutting site, was checked by restriction enzymatic digestion (table 1).

\section{Haplotypic analysis}

Haplotypes were determined by genotyping several affected individuals in each family in order to identify the alleles segregating with the mutation, as previously described ${ }^{8}$ We used all the short tandem repeat markers we had mapped to the VMGLOM locus.'

\section{Multiple alignment of glomulin proteins}

Human and murine glomulin amino acid sequences were retrieved from GenBank database (accession numbers Q92990 and CAD92739, respectively). Protein sequences for chimpanzee, dog, rat, xenopus, and zebrafish were deduced from sequences extracted in silico from EST and genomic sequences, using "Blast" at NCBI (http://www.ncbi.nlm.nih. gov/) and "Blat" at UCSC (http://genome.ucsc.edu/cgi-bin/ hgGateway). These fragmented nucleotidic sequences were first assembled using Sequencher software 4.1.2 (http:// www.genecodes.com/) in order to maximise coverage of the 
Mutation $108 \mathrm{C} \rightarrow \mathrm{A}$
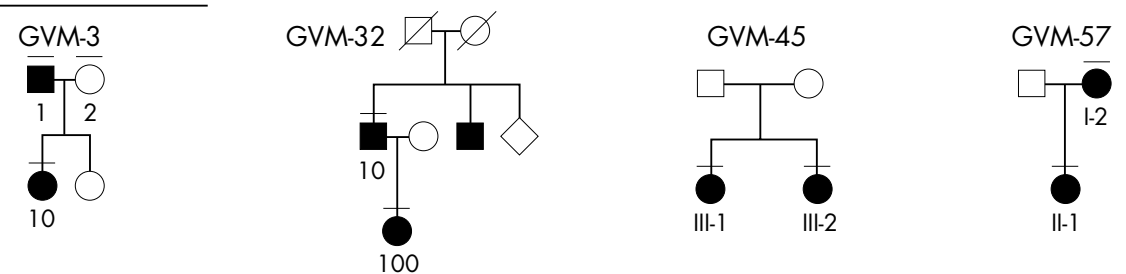

Mutation 157delAAGAA
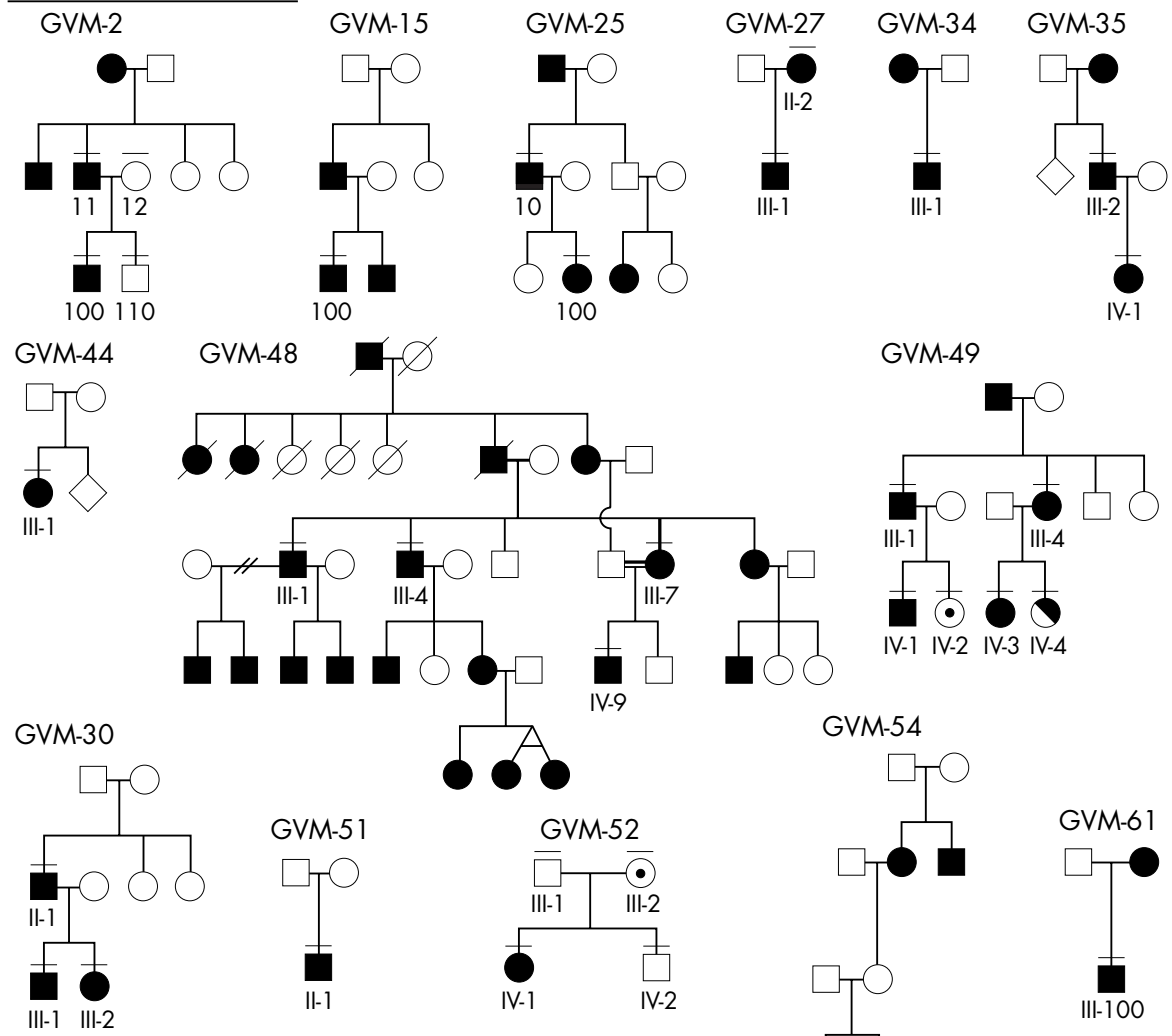

GVM-49
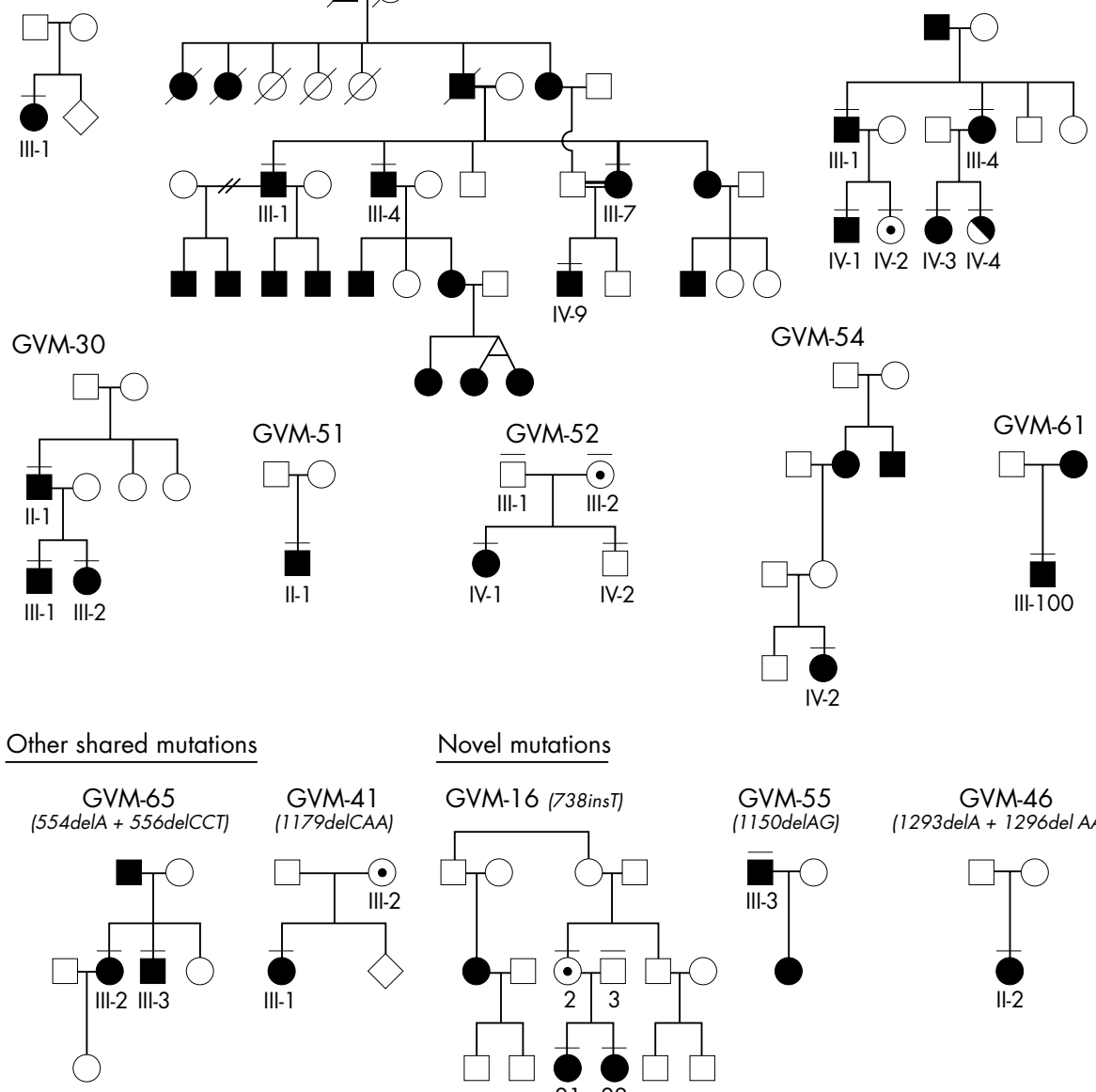

Novel mutations

GVM-16 (738inst)

GVM-55

GVM-54

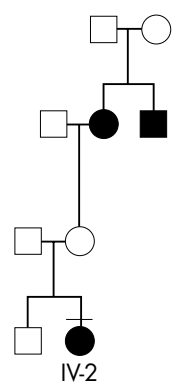

GVM-61

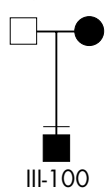

Figure 2 Twenty three new families with inherited glomuvenous malformations (GVM) presented in order of occurrence of mutations in glomulin shared mutations first. Individuals indicated by numbers were tested. Black symbols, affected individuals; dotted symbols, carriers; half black symbols, phenocopies; small horizontal bars indicate individuals examined clinically.

open reading frame. The consensus sequences were then translated into amino acid sequences using DNA Strider 1.0 (http://www.cellbiol.com/DNAStriderl_l_sit.bin). The proteins were aligned using ClustalW (http://www.ebi.ac.uk/ clustalw/) and identical or similar residues were highlighted using Boxshade (http://bioweb.pasteur.fr/seqanal/interfaces/ boxshade.html).

\section{RESULTS}

\section{Identified mutations}

Screening for glomulin mutations on genomic DNA identified the previously described $5 \mathrm{bp}$ deletion 157delAAGAA in 14 new GVM families (figs 2 and 3). Co-segregation analysis showed the deletion in all affected individuals whose DNA was available for testing. Altogether two unaffected carriers 
Table 1 Primers and conditions for detection of the common glomulin mutations by allele specific polymerase chain reaction or restriction enzyme digestion

\begin{tabular}{|c|c|c|c|c|}
\hline & $108 C \rightarrow A$ & 157delAAGAA & $554 \mathrm{del} A+556 \mathrm{del} / \mathrm{CCT}$ & 1179delCAA \\
\hline Forward primer & GATACGTGTGTIATTACGTTAC & GATACGTGTGTTATITACGTTAC & TTGATGAGCGACAACTTGATC & GTGATGAAGTCTGGGTAAGC \\
\hline Reverse primer & ATGTGATTATTCTCTTCCCAAG & ATGTGATTATTCTCTTCCCAAG* & TAAGTCCACTGTGAGATGTTC & AACAATTACATGGCATTAACATG \\
\hline Wt product size & $324 \mathrm{bp}$ & $324 \mathrm{bp}$ & $304 \mathrm{bp}$ & 207 bp \\
\hline $\begin{array}{l}\text { Mutation specific } \\
\text { (=3rd) primer }\end{array}$ & F: AGTTAGCTGGGCAAAGATGA & R: GTACGCACCTTA|TTCATITG & - & R: TTGCCTTGTGAATCCAAC|TTAA \\
\hline Restriction enzyme & - & - & Spe I & - \\
\hline Mutant product(s) & $130 \mathrm{bp}$ & $219 \mathrm{bp}$ & 111 and $193 \mathrm{bp}$ & 117 bp \\
\hline Annealing temp & $55^{\circ} \mathrm{C}$ & $55^{\circ} \mathrm{C}$ & $62^{\circ} \mathrm{C}$ & $58^{\circ} \mathrm{C}$ \\
\hline
\end{tabular}

*Only $50 \%$ of this primer should be used in the allele specific polymerase chain reaction.

I = site of deletion; underlined nucleotide = substitution.

bp, base pair; temp, temperature.

(individuals with a mutation but no lesion) and one presumed phenocopy, with a single lesion of $2 \mathrm{~cm}$ in diameter on the foot, were detected in families GVM-49 and GVM-52 (fig 2). In four other families, we found the previously reported nonsense mutation $108 C \rightarrow A$ (figs 2 and 3). Co-segregation analysis showed this mutation in all affected individuals (fig 2). Two other known mutations were identified: 554delA+556delCCT segregating with the disease in family GVM-65 and 1179delCAA in family GVM-41 (figs 2 and 3 ). In the latter, one obligate carrier was detected (fig 2).

In addition, three novel mutations were discovered, each in one family (fig 2 bottom and fig 3): 738insT, an insertion of a thymidine in exon 8, was detected in family GVM-16 with one unaffected carrier (fig 2); 1150delAG was found in one member of family GVM-55; and one member of family GVM46 harboured the mutation 1293delA+1296delAAA (fig 2). All three mutations cause reading frameshifts that predicted a premature STOP codon in the sequence.

To date, we have identified glomulin mutations in all GVM families tested. 157delAAGAA represents $48.8 \%$ of all the inherited mutations; $108 \mathrm{C} \rightarrow A$ represents $11.8 \%$, and mutations 554delA+556delCCT and $1179 \operatorname{delCAA}$ represent $4.7 \%$ each (fig 4). Thus these four mutations account for $70 \%$ of all GVM families; the remaining $30 \%$ being represented by a mutation unique to each family.

\section{Haplotype analysis}

Haplotype analysis for mutation 157delAAGAA showed that all 21 families with this alteration share a common haplotype for various markers in the VMGLOM locus (fig 5). Based on the alleles, families can be grouped by genetic proximity with

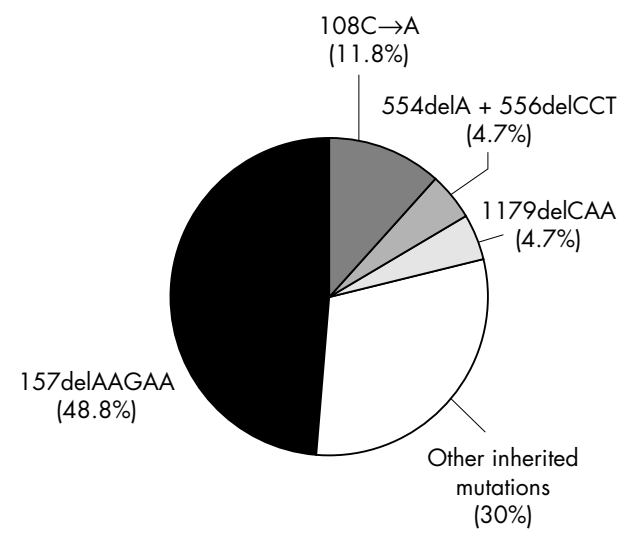

Figure 4 Diagram showing frequency of inherited glomulin mutations. "Other inherited mutations" comprises 13 mutations identified in a single family each.

regard to the VMGLOM locus-for example, families GVM-25, GVM-27 and F, or GVM-2 and GVM-48. The smallest shared area for 157delAAGAA was between polymorphic markers $33 C A 1$ and $75 C A 1$, an area of $825 \mathrm{kbp}$. The distance of marker $33 \mathrm{CAl}$ from the mutation is about $80 \mathrm{kbp}$. Similar haplotype sharing was observed for the five families with $108 \mathrm{C} \rightarrow \mathrm{A}$ mutation, in a region shared between markers D1S188 and DIS236 (fig 5). Families with mutations 554delA+556delCCT and 1179delCAA also showed clear evidence of haplotype sharing (fig 5).

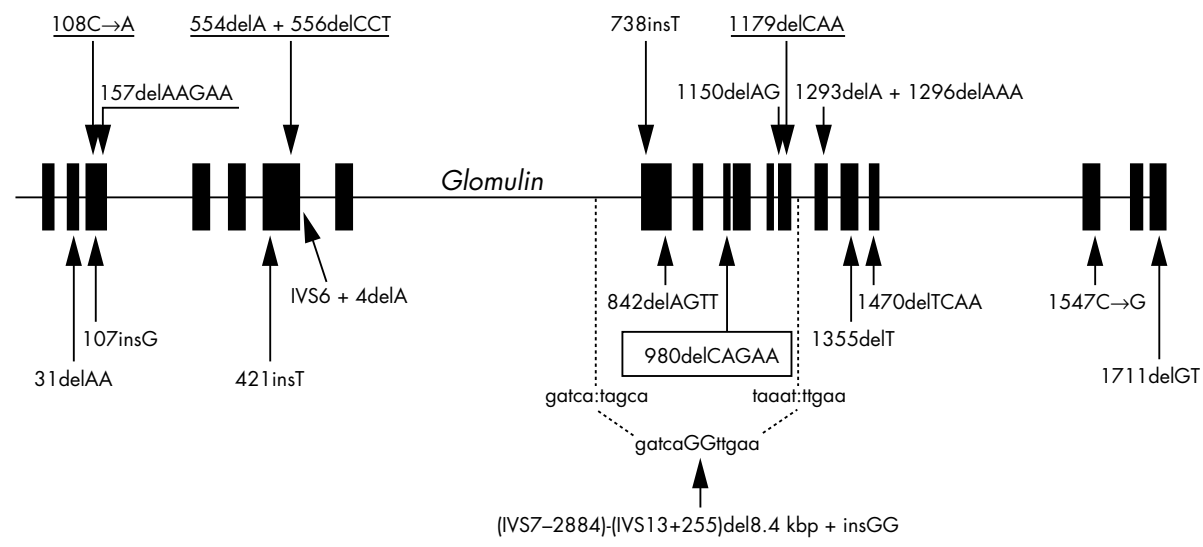

Figure 3 Schematic representation of glomulin summarising all known mutations (adapted from Brouillard et al $\left.\right|^{5}$. Mutations reported here are marked above the gene. Mutations found in more than one family are underlined. Somatic second hit is boxed. 


\section{DISCUSSION}

Four previously known mutations were identified in 20 new families. We also found three novel mutations that would be predicted to cause reading frameshifts and premature truncations.

\section{Founder effect for glomulin mutations}

Mutation 157delAAGAA, previously documented in seven families, ${ }^{5}$ was detected in 14 additional kindreds. The prevalence of this mutation among patients with GVM is thus $48.8 \%$ (fig 4 ). As in the seven previously reported families, ${ }^{8}$ strong haplotype sharing was observed among all 21 white families with this mutation, independent of their country of origin (fig 5). Thus this mutation is a common ancestral alteration. Mutation $108 \mathrm{C} \rightarrow A$, found in family $\mathrm{Ba}$, was detected in four additional families that all share a common haplotype (fig 5). The prevalence was $11.8 \%$ in the GVM families (fig 4). Mutations 554delA+556delCCT and $1179 \operatorname{del} C A A$ were also detected in one new family, giving a prevalence of $4.7 \%$ for each (fig 4 ). Again, haplotype sharing was detected for both mutations (fig 5). Altogether, these four mutations in glomulin were identified in $70 \%$ of the GVM families (fig 4). Although the alterations in the gene cause abnormal cutaneous vascular development, they do not appear to affect reproduction-that is, there is normal endometrial and placental angiogenesis. The high prevalence of these common mutations makes cost-effective genetic testing possible in $70 \%$ of patients (table 1 ).

\section{9 delCAA is an atypical glomulin mutation}

The 1179delCAA mutation, which corresponds to removal of one asparagine at position 394, was identified for the second time. It contrasts with all other mutations that result in premature truncation of glomulin. It could be that the $1179 \operatorname{delCAA}$ allele is unstable or destroyed either at the RNA or at the protein level. Alternatively, the mutation could produce a cryptic splice site and result in premature truncation, as in the case of the "missense" mutations in KRIT- $1 .{ }^{10}{ }^{11}$ However, RT-PCR (reverse transcriptase polymerase chain reaction) on RNA extracted from EBV transformed lymphoblasts (illegitimate transcripts) did not reveal aberrant splicing, and the wild type and mutant alleles were present in equivalent amounts (data not shown). Although the asparagine is not conserved between human and other species (in which it is often an aspartate), most of glomulin is highly conserved and a deletion at this position is not present in known glomulin sequences (fig 6). As individuals with the asparagine 394 deletion have cutaneous lesions indistinguishable from those caused by truncation at whatever site in the protein, it appears that the residue 394 is important for the structure or function of glomulin.

\section{Locus homogeneity for GVM}

The findings in this report underscore our earlier report that premature truncation is most likely to cause loss of function of glomulin. This is the predominant cause of inheritable GVM. Interestingly, mutations were found in members of all families affected by GVM. The four other GVM families that have been studied genetically and reported to date were also shown to link to the VMGLOM locus. ${ }^{12}$ Thus the likelihood of locus heterogeneity for GVM is very small, yet rare variants cannot be excluded.

\section{Double hit explains phenotypic variation}

After the identification of glomulin mutations as the cause of GVM, the questions remained as to why these anomalies are

\begin{tabular}{|c|c|c|c|c|c|c|c|c|c|c|c|c|c|c|c|c|c|c|c|c|c|c|}
\hline \multirow{2}{*}{$\begin{array}{c}\text { Mutation } \\
\text { Family }\end{array}$} & \multirow{3}{*}{$\begin{array}{c}\text { Position } \\
\text { (Mbp) }\end{array}$} & \multicolumn{21}{|c|}{ 157delAAGAA } \\
\hline & & 25 & 27 & $F$ & 35 & 61 & Sch & Sh & 34 & 44 & 54 & Bln & $\mathrm{Bt}$ & 49 & 52 & 51 & 2 & 48 & 50 & $\mathrm{BI}$ & 15 & $\mathrm{~T}$ \\
\hline Origin & & Aus & USA & $\mathrm{Sco}$ & UK & Spa & Ger & USA & Fra & USA & Fra & Fra & $\mathrm{Be}$ & Fra & UK & USA & $\mathrm{Be}$ & Fra & Fra & USA & Aus & Ita \\
\hline A205XD5 & 89.640 & $241 / 245$ & $241 / 245$ & $245 / R$ & 241 & $241 / 245$ & 245 & 245 & $241 / 245$ & $241 / 245$ & 241 & 241 & 239 & 241 & 241 & $241 / 245$ & 239 & 241 & 241 & 241 & $241 / 245$ & 241 \\
\hline D1S435 & 91.026 & 175 & 175 & 175 & 159 & \begin{tabular}{|l|}
$159 / 161$ \\
\end{tabular} & 157 & 161 & $161 / 177$ & $157 / 177$ & 157 & 157 & 157 & 177 & 161 & 161/175 & 161 & $161 / R$ & $175 / R$ & 175 & $157 / 175$ & 175 \\
\hline B337XE1 & 91.435 & 281 & 281 & 281 & 281 & $259 / 263$ & 267 & 267 & $263 / 267$ & 263 & 263 & 263 & 263 & $263 / 267$ & 263 & $259 / 281$ & 263 & 263 & 259 & 263 & 259/267 & 259 \\
\hline D1S188 & 91.968 & 166 & 166 & 166 & $152 / 166$ & $154 / 166$ & 166 & 166 & 166 & $166 / 168$ & $152 / 166$ & 168 & 168 & 168 & 168 & $156 / 162$ & 152 & 152 & 152 & 164 & $166 / 168$ & 166 \\
\hline D1S1170 & 92.014 & 118 & 118 & 118 & 118 & 118 & 118 & 118 & $118 / 126$ & $118 / 122$ & $114 / 118$ & 118 & 118 & 118 & 118 & $118 / 122$ & 118 & $118 / 122$ & 118 & 118 & 122 & 122 \\
\hline 33CA1 & 92.150 & 156 & 156 & 156 & 156 & 156 & 156 & 156 & $142 / 156$ & 156 & $152 / 156$ & 156 & 156 & 156 & 156 & $136 / 156$ & 156 & 156 & $142 / 156$ & 156 & $142 / 152$ & 152 \\
\hline Glomulin & $92.183-92$ & 236 & & & & & & & & & & & & & & & & & & & & \\
\hline D1S424 & 92.352 & 223 & 223 & 223 & 223 & $223 / 225$ & 223 & 223 & $225 / 227$ & $209 / 223$ & $209 / 223$ & 225 & 225 & 225 & 223 & 223 & 223 & 223 & 223 & 223 & $23 / 227$ & 223 \\
\hline $\begin{array}{l}\mathrm{D} 1 \mathrm{~S} 2804 \\
\end{array}$ & 92.353 & 179 & 179 & 179 & 179 & 179 & 179 & 179 & 179/191 & $179 / 185$ & $179 / 185$ & 179 & 179 & 179 & 179 & 179 & 179 & 179 & 179 & 179 & - & 179 \\
\hline D1S406 & 92.499 & 200 & 200 & 204 & 200 & $200 / 212$ & 200 & 200 & $200 / 208$ & $200 / 208$ & $196 / 200$ & 196 & 200 & 200 & 204 & $200 / 208$ & 200 & $200 / 204$ & 200 & 200 & $204 / 208$ & 200 \\
\hline 69CA1 & 92.544 & 171 & 171 & 171 & 171 & 171 & 171 & 171 & 169/171 & $169 / 171$ & $169 / 171$ & 171 & 169/171 & 169/171 & $171 / 175$ & 171 & 171 & 171 & 171 & 171 & 169/171 & 171 \\
\hline D1S2776 & 92.682 & 206 & 206 & 206 & 206 & $206 / 210$ & 206 & 206 & $194 / 206$ & $196 / 206$ & $194 / 206$ & 206 & 206 & 206 & 206 & $206 / 210$ & 206 & 206 & 206 & 206 & 194/206 & 206 \\
\hline $50 \mathrm{CA} 1$ & 92.735 & 127 & 127 & 127 & 127 & $121 / 127$ & 127 & 129 & $125 / 127$ & $125 / 127$ & 127 & 127 & $125 / 127$ & $125 / 127$ & 127 & $119 / 127$ & 127 & 127 & 127 & 127 & $121 / 127$ & 127 \\
\hline D1S2868 & 92.807 & 146 & 146 & 146 & 146 & $146 / 150$ & 146 & 146 & $144 / 146$ & $146 / 148$ & $144 / 146$ & 146 & 146 & 146 & 146 & $146 / 150$ & 146 & 146 & 146 & 146 & $146 / 148$ & 146 \\
\hline 75CA1 & 92.975 & $171 / 173$ & $171 / 173$ & 173 & $171 / 173$ & $171 / 173$ & 173 & 173 & 173 & $169 / 173$ & $171 / 173$ & 173 & $171 / 173$ & 173 & 173 & $173 / 176$ & 173 & 173 & 173 & $171 / 173$ & & 171 \\
\hline D1S2849b & 92.991 & 179 & 179 & 179 & 179 & 175/179 & 179 & 179 & $177 / 179$ & 179 & $179 / 181$ & 179 & 179 & 179 & 179 & $177 / 179$ & 179 & 179 & 179 & 179 & 179/181 & 179 \\
\hline D1S2779 & 93.172 & 231 & $227 / 231$ & 231 & 231 & $229 / 231$ & 231 & 233 & $231 / 243$ & $229 / 231$ & 231 & 231 & 231 & 231 & 231 & $231 / 237$ & 231 & 231 & 229 & 229 & $231 / 241$ & 241 \\
\hline D1S236 & 94.282 & 190 & 190 & 190 & 214 & $190 / 214$ & 212 & 194 & 212 & 194/218 & |194/212 & 190 & 210 & 212 & 194 & 190 & 212 & 214 & 214 & 194 & 194 & 212 \\
\hline $\mathrm{D} 1 \mathrm{~S} 2775$ & 94.717 & 201 & $201 / 205$ & 201 & $201 / 205$ & 199/203 & 201 & 201 & $201 / 205$ & 201 & $197 / 199$ & 199/201 & 201/205 & 203 & 197/199 & $197 / 199$ & 199/201 & 199/201 & \begin{tabular}{|l|}
$199 / 201$ \\
\end{tabular} & 199/201 & - & 201 \\
\hline
\end{tabular}

\begin{tabular}{|c|c|c|c|c|c|c|}
\hline \multirow{2}{*}{$\begin{array}{c}\text { Mutation } \\
\text { Family } \\
\end{array}$} & & \multicolumn{5}{|c|}{$108 C>A$} \\
\hline & \multirow{2}{*}{$\begin{array}{c}\text { Position } \\
\text { (Mbp) }\end{array}$} & 45 & 57 & 3 & $\mathrm{Ba}$ & 32 \\
\hline Origin & & USA & Aus & USA & Yug & Aus \\
\hline \begin{tabular}{|l} 
A205XD5 \\
\end{tabular} & 89.640 & 241 & 241 & 241 & 241 & 239 \\
\hline D1S435 & 91.026 & 157 & 157/161 & 157 & 157 & 157 \\
\hline B337XE1 & 91.435 & $263 / 267$ & 267 & 267 & $259 / 267$ & 259 \\
\hline D1S188 & 91.968 & 158 & 154 & 158 & $156 / 162$ & $152 / 156$ \\
\hline D1S1170 & 92.014 & 118 & 118 & 118 & $118 / 122$ & 118 \\
\hline 33CA1 & 92.150 & 156 & 156 & 156 & 156 & 156 \\
\hline Glomulin & $92.183-92$ & 236 & & & & \\
\hline D1S424 & 92.352 & 209 & 209 & 209 & 209 & $209 / 223$ \\
\hline D1S2804 & 92.353 & 185 & 185 & 185 & 185 & 185 \\
\hline D1S406 & 92.499 & 208 & 208 & 208 & 204/208 & 208 \\
\hline 69CA1 & 92.544 & 169 & 169 & 169 & 169 & 169 \\
\hline \begin{tabular}{|l} 
D1S2776 \\
\end{tabular} & 92.682 & 196 & 194/196 & 196 & $196^{*}$ & $196 / 210$ \\
\hline 50CA1 & 92.735 & 125 & 125 & 125 & 125 & 125 \\
\hline \begin{tabular}{|l|} 
D1S2868 \\
\end{tabular} & 92.807 & 148 & 148 & 148 & 148 & 148 \\
\hline 75CA1 & 92.975 & 171 & 171 & 171 & 171 & 171 \\
\hline D1S2849b & 92.991 & 179 & 179 & 179 & 179 & 179 \\
\hline \begin{tabular}{|l|} 
D1S2779 \\
\end{tabular} & 93.172 & 233 & 233 & 233 & 233 & 233 \\
\hline D1S236 & 94.282 & 190 & 190 & 216 & $194 / 212$ & 194 \\
\hline D1S2775 & 94.717 & 199 & 199 & 201 & $197 / 201$ & 199 \\
\hline
\end{tabular}

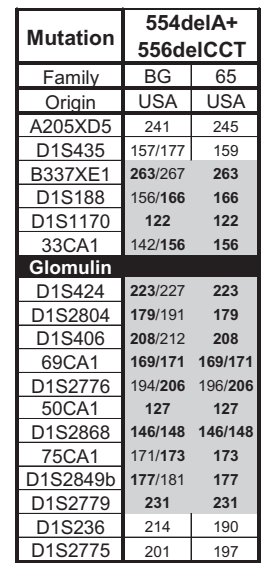

Figure 5 Haplotypes showing strong founder effect for the four common glomulin mutations. Numbers indicate size of the allele(s) segregating with the disorder. Alleles shared between families are indicated by grey shading. Families were grouped by maximising proximity. Location of glomulin is marked in black. Physical position of markers is given according to the July 2003 genome assembly of UCSC. Note that order of markers DIS424 and DIS2804 was inverted compared with previous reports. The origin of the families is shown at the top: Arg, Argentina; Aus, Australia; Be, Belgium; Fra, France; Ger, Germany; Ita, Italy; Sco, Scotland; Spa, Spain; UK, United Kingdom; USA, United States of America; Yug, Yugoslavia. Note that sizes of shared alleles for marker DIS188 are 2 bp larger than previously reported for families $\mathrm{Ba}$ and $\mathrm{B} \mid{ }^{8}$ 

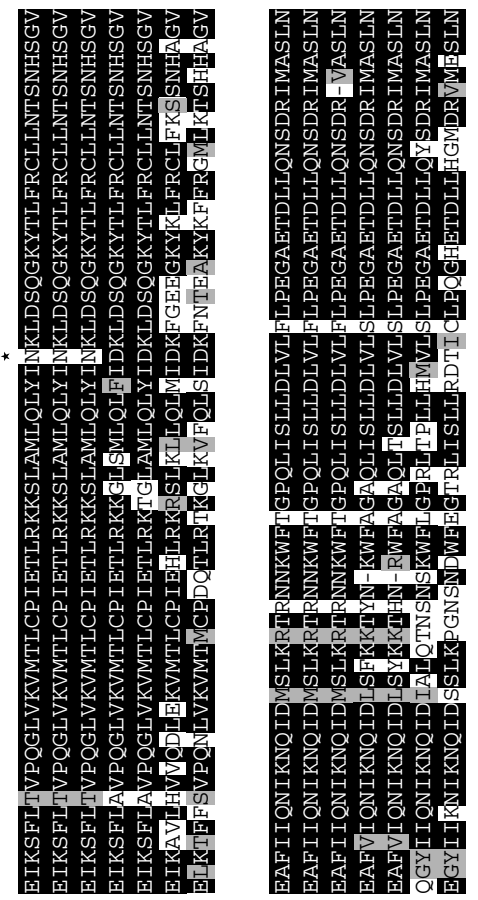

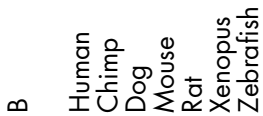
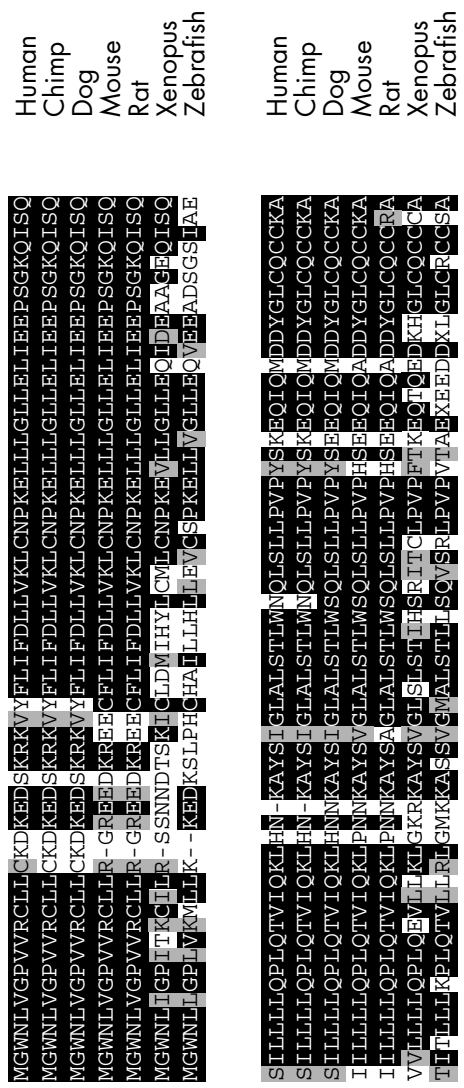

《

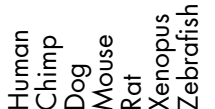
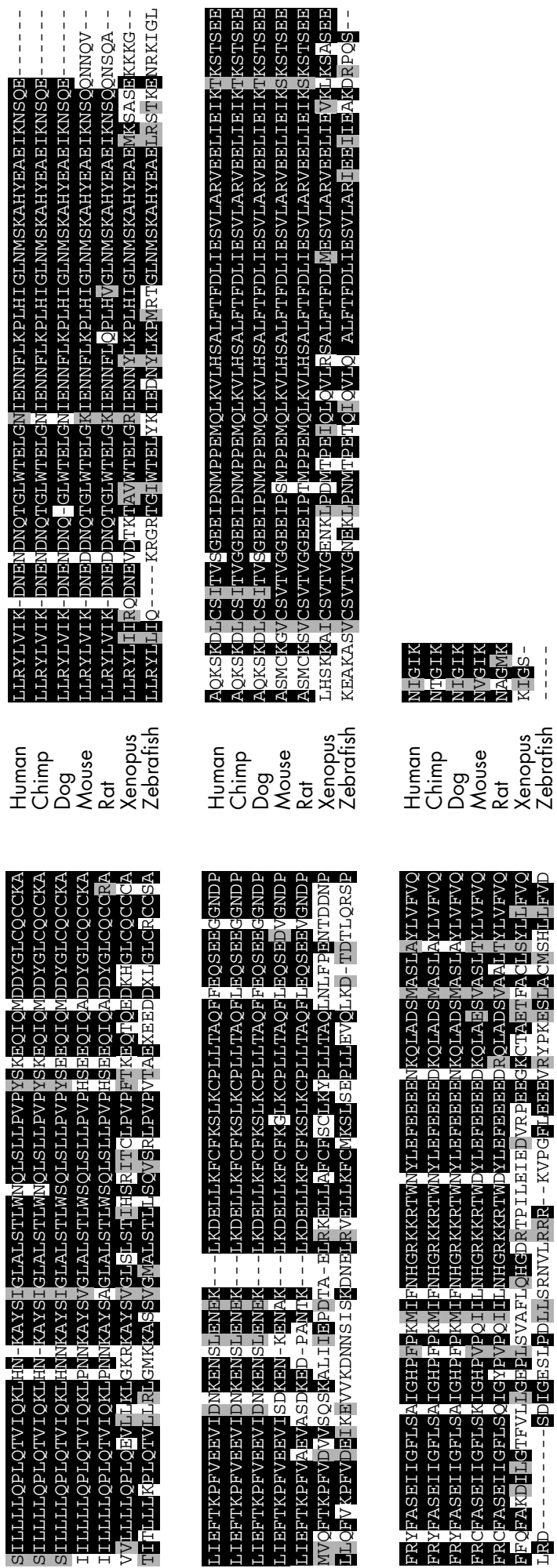

든

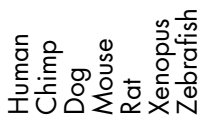

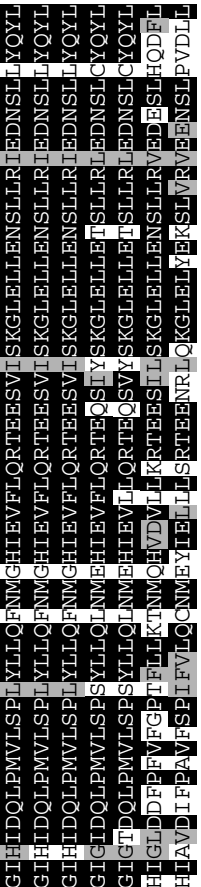

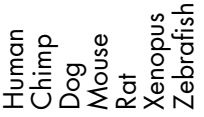

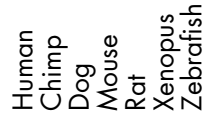

Figure 6 Multiple alignment of glomulin proteins of different species (known or deduced from fragments of nucleotidic sequences found in databases) showing high degree of homology. Identical residues are boxed in black and similar ones in grey. The asterisk indicates the asparagine (N) 394 lost because of mutation 1179 delCAA. 
multifocal instead of arising in all veins, and why only in the skin? According to our data, there is no phenotype-genotype correlation-that is, the position of a mutation in glomulin does not explain the clinical findings, such as localisation, extent, or number of lesions. Moreover, for the same germline mutation, the expressivity is variable from family to family and from patient to patient (fig 1). Frequently, a single individual in a family is more severely affected and is brought to medical attention, whereas most of the other affected individuals have small lesions and have never considered treatment. ${ }^{2}$ We have proposed that Knudson's double hit model could explain this variation. ${ }^{5}{ }^{13}$ Support for this hypothesis was the discovery of a somatic mutation-a second hit affecting the "normal" allele-in one resected GVM lesion, resulting in a complete localised loss of function of glomulin. ${ }^{5}$ This paradominant mode of inheritance would explain the presence of the 22 unaffected carriers in our series (fig 2 and Brouillard $e t a l^{5}$ ), and is underscored by the age dependent variation in penetrance, which reaches its maximum $(92.7 \%)$ by 20 years. ${ }^{5}$ If no second hit occurs in a cell in which the function of glomulin is important (likely to be the vascular smooth muscle cells), no lesion would develop. Thus the localisation, size, and number of lesions are defined by the random occurrence of post-zygotic mutations. This also suggests that somatic mutations early in development would result in larger, segmental lesions, whereas mutations occurring later in development would only cause small punctate lesions. The low frequency of extensive lesions $(>5 \mathrm{~cm})$ and the high frequency of localised lesions $(<5 \mathrm{~cm})$ observed in GVM patients fit this model. ${ }^{2}$ The double hit proposal would also explain the multifocality of the lesions as the result of several independent somatic mutations. This is supported by the fact that $17 \%$ of affected individuals develop new lesions in time. ${ }^{2}$ However, these all stay small. What is not clear is whether non-hereditary GVM exists and why only cutaneous and subcutaneous veins are affected.

The two hit scenario may also apply to other inheritable vascular anomalies for which loss of function is predicted, ${ }^{13}$ such as cutaneous and cerebral capillary-venous malformation (CCM) caused by mutations in the KRITI or malcavernin gene, ${ }^{14-17}$ capillary malformation-arteriovenous malformation (CM-AVM) caused by mutations in RASAl, ${ }^{18}$ and even congenital lymphoedema caused by loss of function mutations in the VEGFR3 receptor. ${ }^{19}{ }^{20}$ For CCM, two different somatic mutations have been reported in KRIT- 1 in a tissue sample. ${ }^{21}$

GVM: a primary vascular smooth muscle cell defect? Mural "glomus cells" are pathognomonic for GVM. It seems that the localised complete loss of function of glomulin alters recruitment and differentiation of vascular smooth muscle cells. Our developmental in situ hybridisation studies on murine embryos reinforce this idea. ${ }^{22}$ Glomulin expression was mainly identified in vascular smooth muscle cells during development. ${ }^{22}$ The expression was particularly obvious in large arteries and veins, and yet patients with GVM do not have structural abnormalities of the major blood vessels.

The signalling pathways involving glomulin remain unknown. The best candidates are the transforming growth factor $\beta$ (TGF $\beta$ ) pathway, through a possible interaction of glomulin with the immunophilin FKBP12, ${ }^{23-25}$ and the hepatocyte growth factor (HGF) pathway, by direct interaction with the HGF receptor c-MET and activation of the p70S6 kinase. ${ }^{25}$ In both instances, loss of function of glomulin may result in alteration of the signalling pathway, and could provide targets for therapy. Glomulin was also reported to interact with Cul7, knockout of which presents with cutaneous haemorrhages. ${ }^{26}$ Interestingly, for inherited mucocutaneous venous malformations which are caused by activating mutations in the angiopoietin receptor TIE2/TEK, there are diminished numbers of vascular smooth muscle cells. ${ }^{27}$ Thus in both disorders venous dilatation may simply be secondary to decreased or altered mural cellular support.

\section{Conclusions}

All glomulin mutations identified up to now indicate that familial GVM lesions are caused by loss of function in a paradominant fashion. Seventy per cent of families with inherited GVM share one of the four common mutations, whereas the other $30 \%$ have unique mutations. Thus screening of these four common mutations should be the first step in molecular diagnosis of a patient thought to have GVM.

\section{ACKNOWLEDGEMENTS}

We are grateful to all the patients for their participation in this study. The research was supported by the Fonds Spéciaux de Recherche Université catholique de Louvain, the Interuniversity Attraction Poles initiated by the Belgian Science Policy, network 5/25, the National Institutes of Health, program project P01 AR048564-01Al, the Actions de Recherche Concertées - Communauté Française de Belgique and the FNRS (Fonds national de la recherche scientifique) to MV, a chercheur qualifié du FNRS. PB, currently a postdoctoral researcher of FNRS, was also supported by fellowships from the FRIA (Fonds pour la formation à la recherche dans l'industrie et dans l'agriculture) and from the Université catholique de Louvain. MG was supported by a fellowship from the John Butler Mulliken Foundation and currently from the FRIA. We thank Ms Ana Gutierrez and Ms Dominique Cottem for their expert technical assistance, and Ms Liliana Niculescu for secretarial help.

\section{Authors' affiliations}

P Brouillard, M Ghassibé, M Vikkula, Laboratory of Human Molecular Genetics, Christian de Duve Institute of Cellular Pathology and Université catholique de Louvain, Brussels, Belgium

A Penington, University of Melbourne, Department of Surgery, St Vincent's Hospital, Melbourne, Australia

L M Boon, Centre of Vascular Anomalies, Division of Plastic Surgery, Université catholique de Louvain, Brussels, Belgium

A Dompmartin, Dermatologie, Centre Hospitalier Universitaire, Caen, France

I K Temple, Wessex Clinical Genetics Service and Division of Human Genetics, Southampton University and Hospital NHS Trust,

Southampton, UK

M Cordisco, Hospital Nacional de Pediatria, Buenos Aires, Argentina D Adams, Department of Pediatrics, Children's Hospital Medical Center, University of Cincinnati, Ohio, USA

F Piette, Clinique de Dermatologie, Centre Hospitalier Regional Universitaire, Lille, France

J I Harper, S Syed, Great Ormond Street Hospital for Children NHS Trust, London, UK

F Boralevi, A Taïeb, Unité de Dermatologie Pédiatrique, Hôpital Pellegrin-Enfants, CHU, Bordeaux, France

S Danda*, South Australian Clinical Genetics Service, Women's \& Children's Hospital, North Adelaide, South Australia

E Baselga, Department of Dermatology, Hospital de la Santa Creu i Sant Pau, Universitat Autonoma de Barcelona, Barcelona, Spain

O Enjolras, Consultations des Angiomes, Hôpital Lariboisière, Paris, France

J B Mulliken, Division of Plastic Surgery, Vascular Anomalies Center, Children's Hospital, Harvard Medical School, Boston, Massachusetts, USA

*Dr S Danda's current address: Wellcome Research Unit, Christian Medical College Hospital, Vellore, Tamil Nadu, India

Conflicts of interest: none declared

Correspondence to: Professor Miikka Vikkula, Laboratory of Human Molecular Genetics, Christian de Duve Institute of Cellular Pathology and Université catholique de Louvain, Avenue Hippocrate 74, BP 75.39, B-1200 Brussels, Belgium; vikkula@bchm.ucl.ac.be

Received in revised form 20 August 2004

Accepted for publication 23 August 2004 


\section{REFERENCES}

1 Laymon CW, Peterson WC. Glomangioma (glomus tumor). Arch Dermatol 1965;92:509-14

2 Boon LM, Mulliken JB, Enjolras O, Vikkula M. Glomuvenous malformation (glomangioma) and venous malformation. Arch Dermatol 2004;140:971-6.

3 Boon LM, Brouillard P, Irrthum A, Karttunen L, Warman ML, Rudolph R, Mulliken JB, Olsen BR, Vikkula M. A gene for inherited cutaneous venous anomalies ("glomangiomas") localizes to chromosome 1p21-22. Am J Hum Genet 1999:65:125-33.

4 Vikkula M, Boon LM, Mulliken JB. Molecular genetics of vascular malformations. Matrix Biol 2001;20:327-35.

5 Brouillard P, Boon LM, Mulliken JB, Enjolras O, Ghassibe M, Warman ML, Tan OT, Olsen BR, Vikkula M. Mutations in a novel factor, glomulin, are responsible for glomuvenous malformations ("glomangiomas"). Am J Hum Genet 2002;70:866-74.

6 Kato N, Kumakiri M, Ohkawara A. Localized form of multiple glomus tumors: report of the first case showing partial involution. J Dermatol 1990; 17:423-8.

7 Goodman TF, Abele DC. Multiple glomus tumors. A clinical and electron microscopic study. Arch Dermatol 1971;103:11-23.

8 Irrthum A, Brouillard P, Enjolras O, Gibbs NF, Eichenfield LF, Olsen BR, Mulliken JB, Boon LM, Vikkula M. Linkage disequilibrium narrows locus for venous malformation with glomus cells (VMGLOM) to a single 1.48 Mbp YAC. Eur J Hum Genet 2001:9:34-8.

9 Brouillard P, Olsen BR, Vikkula M. High-resolution physical and transcript map of the locus for venous malformations with glomus cells (VMGLOM) on chromosome 1p21-p22. Genomics 2000;67:96-101.

10 Cave-Riant F, Denier C, Labauge P, Cecillon M, Maciazek J, Joutel A, Laberge-Le Couteulx S, Tournier-Lasserve E. Spectrum and expression analysis of KRIT1 mutations in 121 consecutive and unrelated patients with Cerebral Cavernous Malformations. Eur J Hum Genet 2002;10:733-40.

11 Verlaan DJ, Siegel AM, Rouleau GA. Krit1 missense mutations lead to splicing errors in cerebral cavernous malformation. Am J Hum Genet 2002;70:1564-7.

12 Calvert JT, Burns S, Riney TJ, Sahoo T, Orlow SJ, Nevin NC, Haisley-Royster C, Prose N, Simpson SA, Speer MC, Marchuk DA. Additional glomangioma families link to chromosome 1p: No evidence for genetic heterogeneity. Hum Hered 2001;51:180-2.

13 Brouillard $\mathbf{P}$, Vikkula M. Vascular malformations: localized defects in vascular morphogenesis. Clin Genet 2003;63:340-51.

14 Eerola I, Plate KH, Spiegel R, Boon LM, Mulliken JB, Vikkula M. KRIT1 is mutated in hyperkeratotic cutaneous capillary-venous malformation associated with cerebral capillary malformation. Hum Mol Genet 2000:9:1351-5.

15 Sahoo T, Johnson EW, Thomas JW, Kuehl PM, Jones TL, Dokken CG Touchman JW, Gallione CJ, Lee-Lin SQ, Kosofsky B, Kurth JH, Louis DN Mettler G, Morrison L, Gil-Nagel A, Rich SS, Zabramski JM, Boguski MS Green ED, Marchuk DA. Mutations in the gene encoding KRIT1, a Krev-1/ rapla binding protein, cause cerebral cavernous malformations (CCM1). Hum Mol Genet 1999;8:2325-33.

16 Liquori CL, Berg MJ, Siegel AM, Huang E, Zawistowski JS, Stoffer T, Verlaan D, Balogun F, Hughes L, Leedom TP, Plummer NW, Cannella M, Maglione V, Squitieri F, Johnson EW, Rouleau GA, Ptacek L, Marchuk DA Mutations in a gene encoding a novel protein containing a phosphotyrosinebinding domain cause type 2 cerebral cavernous malformations. Am J Hum Genet 2003;73:1459-64.

17 Denier C, Goutagny S, Labauge P, Krivosic V, Arnoult M, Cousin A, Benabid AL, Comoy J, Frerebeau P, Gilbert B, Houtteville JP, Jan M, Lapierre F, Loiseau H, Menei P, Mercier P, Moreau JJ, Nivelon-Chevallier A, Parker F, Redondo AM, Scarabin JM, Tremoulet M, Zerah M, Maciazek J, TournierLasserve E. Mutations within the MGC4607 gene cause cerebral cavernous malformations. Am J Hum Genet 2004;74:326-37.

18 Eerola I, Boon LM, Mulliken JB, Burrows PE, Dompmartin A, Watanabe S, Vanwijck R, Vikkula M. Capillary malformation-arteriovenous malformation, a new clinical and genetic disorder caused by RASAI mutations. Am J Hum Genet 2003;73:1240-9.

19 Irrthum A, Karkkainen MJ, Devriendt K, Alitalo K, Vikkula M. Congenital hereditary lymphedema caused by a mutation that inactivates VEGFR3 tyrosine kinase. Am J Hum Genet 2000;67:295-301.

20 Karkkainen MJ, Ferrell RE, Lawrence EC, Kimak MA, Levinson KL, McTigue MA, Alitalo K, Finegold DN. Missense mutations interfere with VEGFR-3 signalling in primary lymphoedema. Nat Genet 2000;25:153-9.

21 Kehrer-Sawatzki H, Wilda M, Braun VM, Richter HP, Hameister H Mutation and expression analysis of the KRITl gene associated with cerebral cavernous malformations (CCM1). Acta Neuropathol (Berl) 2002;104:231-40

22 McIntyre BA, Brouillard P, Aerts V, Gutierrez-Roelens I, Vikkula M. Glomulin is predominantly expressed in vascular smooth muscle cells in the embryonic and adult mouse. Gene Expr Patterns 2004;4:351-8.

23 Chambraud B, Radanyi C, Camonis JH, Shazand K, Rajkowski K, Baulieu EE. FAP48, a new protein that forms specific complexes with both immunophilins FKBP59 and FKBP12. Prevention by the immunosuppressant drugs FK506 and rapamycin. J Biol Chem 1996;271:32923-9.

24 Chen YG, Liu F, Massague J. Mechanism of TGFbeta receptor inhibition by FKBP12. Embo J 1997; 16:3866-76.

25 Grisendi S, Chambraud B, Gout I, Comoglio PM, Crepaldi T. Ligandregulated binding of FAP68 to the hepatocyte growth factor receptor. J Biol Chem $2001 ; 276: 46632-8$

26 Arai T, Kasper JS, Skaar JR, Ali SH, Takahashi C, DeCaprio JA. Targeted disruption of p185/Cul7 gene results in abnormal vascular morphogenesis. Proc Natl Acad Sci U S A 2003;100:9855-60.

27 Vikkula M, Boon LM, Carraway KL, Calvert JT, Diamonti AJ, Goumnerov B, Pasyk KA, Marchuk DA, Warman ML, Cantley LC, Mulliken JB, Olsen BR. Vascular dysmorphogenesis caused by an activating mutation in the receptor tyrosine kinase TIE2. Cell 1996;87:1181-90. 